\title{
Two new and distinct roles for Drosophila Argonaute-2 in the nucleus: alternative pre-mRNA splicing and transcriptional repression
}

\author{
J. Matthew Taliaferro, ${ }^{1}$ Julie L. Aspden, ${ }^{1}$ Todd Bradley, ${ }^{2,3}$ Dhruv Marwha, ${ }^{1}$ Marco Blanchette, ${ }^{2,3}$ \\ and Donald C. Rio ${ }^{1,4,5,6}$ \\ ${ }^{1}$ Department of Molecular and Cell Biology, University of California at Berkeley, Berkeley, California 94720, USA; ${ }^{2}$ Stowers \\ Institute for Medical Research, Kansas City, Missouri 64110, USA; ${ }^{3}$ Department of Pathology and Laboratory Medicine, \\ University of Kansas Medical Center, Kansas City, Kansas 66160, USA; ${ }^{4}$ Center for Integrative Genomics, ${ }^{5}$ California Institute \\ for Quantitative Biosciences (QB3), University of California at Berkeley, Berkeley, California 94720, USA
}

Transcription and pre-mRNA alternative splicing are highly regulated processes that play major roles in modulating eukaryotic gene expression. It is increasingly apparent that other pathways of RNA metabolism, including small RNA biogenesis, can regulate these processes. However, a direct link between alternative premRNA splicing and small RNA pathways has remained elusive. Here we show that the small RNA pathway protein Argonaute-2 (Ago-2) regulates alternative pre-mRNA splicing patterns of specific transcripts in the Drosophila nucleus using genome-wide methods in conjunction with RNAi in cell culture and Ago-2 deletion or catalytic site mutations in Drosophila adults. Moreover, we show that nuclear Argonaute-2 binds to specific chromatin sites near gene promoters and negatively regulates the transcription of the Ago-2-associated target genes. These transcriptional target genes are also bound by Polycomb group (PcG) transcriptional repressor proteins and change during development, implying that Ago-2 may regulate Drosophila development. Importantly, both of these activities were independent of the catalytic activity of Ago-2, suggesting new roles for Ago-2 in the nucleus. Finally, we determined the nuclear RNA-binding profile of Ago-2, found it bound to several splicing target transcripts, and identified a G-rich RNA-binding site for Ago-2 that was enriched in these transcripts. These results suggest two new nuclear roles for Ago-2: one in pre-mRNA splicing and one in transcriptional repression.

[Keywords: alternative splicing; transcription; RNA; Drosophila; Argonaute]

Supplemental material is available for this article.

Received November 20, 2012; revised version accepted January 7, 2013.

Small RNAs have been known for some time to play vital roles in RNA-mediated regulation, beginning with the discovery of their role in developmental regulation in Caenorhabditis elegans (Lee et al. 1993; Wightman et al. 1993). In Drosophila, there is a functional separation between the pathway that produces microRNAs, which tend to act without cleaving the target mRNA, and the pathway that produces siRNAs, which tend to involve cleavage of the target endogenous or viral mRNA (Forstemann et al. 2007; Tomari et al. 2007). This separation is based on the level of complementarity between the strands of the dsRNA (Tomari et al. 2007).

${ }^{6}$ Corresponding author

E-mail don_rio@berkeley.edu

Article published online ahead of print. Article and publication date are online at http://www.genesdev.org/cgi/doi/10.1101/gad.210708.112.
Although Argonaute-1 (Ago-1)-bound microRNAs arise from specific genomic loci, Ago-2-bound siRNAs can originate from several different sources. Viral RNA replication intermediates, convergent transcription events, and complementary regions in different transcripts can all lead to the formation of functional dsRNA that can be cleaved by Dicer-2 and loaded into Ago-2 (Czech et al. 2008; Kawamura et al. 2008). This opens up a large part of the genome to potential small RNA-mediated regulation.

A few examples of splicing regulation through small RNAs have already been reported. The splicing of the serotonin receptor $2 \mathrm{C}$ gene in human tissue culture cells has been shown to be affected by the snoRNA HBII-52 in a base-pairing-dependent manner between the snoRNA and the serotonin receptor 2C pre-mRNA (Kishore and Stamm 2006). This principle has also been used in a therapeutic setting to modulate the splicing of the SMN2 gene, which in humans can be inefficiently cor- 
rectly spliced (Hua et al. 2011). Using antisense oligos targeting the SMN2 pre-mRNA, the productive splicing efficiency could be increased, leading to the production of more functional SMN2 protein (Hua et al. 2010, 2011).

Previous work in other organisms has also demonstrated links between chromatin state, histone marks, and alternative splicing (Spies et al. 2009). These studies showed that these effects are mediated through recruitment of factors to specific histone marks (Luco et al. 2010; Pradeepa et al. 2012) or by modulating the rate of transcription through certain chromatin regions (Batsche et al. 2006). Some of these effects were also shown to be dependent on Argonaute-1 and siRNA-mediated transcriptional gene silencing in human cells (Allo et al. 2009). Links between RNAi components and chromatin structure have also been made in other systems, including Drosophila and Schizosaccharomyces pombe (Buhler and Moazed 2007; Pushpavalli et al. 2012).

It has been shown that Argonaute family members in other organisms can bind throughout the length of premRNA transcripts (Chi et al. 2009; Zisoulis et al. 2010; Leung et al. 2011). Interestingly, there are also hints of a small RNA-independent mode of mouse Argonaute-2 mRNA binding (Leung et al. 2011).

An interplay between the splicing and small RNA machineries has been shown to exist in Drosophila cells. In a genome-wide screen, several splicing factors, including PSI (P-element splicing inhibitor) and snRNP70K, were shown to have an influence on the production or efficacy of either microRNAs or siRNAs (Zhou et al. 2008). We now ask the reciprocal question: Do the components of the small RNA pathway have an effect on the output of the splicing machinery? We found that Ago-2, but not Dicer-2, regulates many splice junctions in Drosophila. Furthermore, we found that Ago-2 binds at the promoter region of genes and acts as a transcriptional repressor in conjunction with PcG proteins and that this repression is independent of its catalytic slicer activity. Finally, we used cross-linking and immunoprecipitation (CLIP) sequencing (CLIP-seq) on nuclear extract to determine the nuclear RNA-binding profile of Ago-2 in Drosophila tissue culture cells.

\section{Results}

Drosophila Argonaute-2 regulates nuclear alternative pre-mRNA splicing patterns in $S 2$ cells

We investigated the effects that four Drosophila small RNA-related proteins-Dicer-1 (Dcr-1), Dicer-2 (Dcr-2), Ago-1, and Ago-2-had on pre-mRNA splicing patterns in Drosophila tissue culture cells by first using RNAi to knock down expression of each protein and then analyzing the resulting RNA by splice junction microarray (Blanchette et al. 2005, 2009; Taliaferro et al. 2011). Importantly, RNAi knockdown of components of the RNAi pathway themselves was possible and efficient, as evidenced by knockdown efficiencies of $>90 \%$ (Supplemental Fig. 1A). The knockdown of Dcr-1, Dcr-2, and Ago-1 had very modest effects on alternative splicing and only resulted in changes in splicing efficiency of 12 , four, and two splice junctions, respectively. In contrast, the knockdown of Ago-2 resulted in changes at 116 junctions (Fig. 1A), a number similar to the splicing changes seen upon knockdown of known splicing factors (Blanchette et al. 2005, 2009). Several of these splicing changes were validated using semiquantitative RT-PCR (Supplemental Fig. 1B). The observed splicing changes after knockdown of Ago-2 were not seen after knockdown of Dcr-1, Dcr-2, or Ago-2 (Supplemental Fig. 1C).

We then set out to address whether the knockdown of Ago-2 was leading to changes in splicing through a direct or indirect mechanism. If Ago-2 directly affects premRNA splicing, we reasoned that Ago-2 must be at least partially nuclear-localized. We fractionated Drosophila S2 cells into cytoplasmic, nucleoplasmic, and chromatinassociated fractions. Using immunoblotting, we detected Ago-2 in all three fractions (Fig. 1B). We also detected Ago-2 in the nucleus of Drosophila Kc cells, although to a lesser extent. We also created a Drosophila S2 cell line that expressed Flag-tagged Ago-2 under the control of an inducible promoter. We induced expression of this tagged Ago-2 such that the expression of the transgene was very low compared with the expression of endogenous Ago-2 (data not shown). We detected, by immunoblotting with an antiFlag antibody, localization of Ago-2 in all three subcellular fractions of this cell line as well (Supplemental Fig. 1D).

To determine whether Ago-2 binds the splicing target transcripts shown by the splice junction microarray in vivo, we cross-linked RNA-protein complexes using $0.05 \%$ formaldehyde and then immunoprecipitated complexes containing Ago-2 using a specific monoclonal antibody (Miyoshi et al. 2005). We detected an enrichment of transcripts whose splicing was affected by Ago-2 in the Ago-2 immunoprecipitations compared with the input and control immunoprecipitations (Fig. 1C; Supplemental Fig. 1E). Conversely, two transcripts shown not to be splicing targets of Ago-2 were not enriched in the Ago-2 immunoprecipitations (Supplemental Fig. 1F).

Data from the splice junction microarrays were also used to determine the change in RNA expression level for $84 \%$ of Drosophila genes upon Ago-2 knockdown (Supplemental Fig. 1G). Of the 51 genes whose mRNA expression levels changed, only one, hrp36, was a known splicing factor. The mRNA expression of hrp36 decreased approximately twofold upon Ago-2 knockdown. However, the overall change in expression of all genes upon Ago-2 knockdown was unlike that observed upon knockdown of any other tested splicing factor, including hrp36, demonstrating that Ago-2 most likely mediates changes in splicing independent of its role in modulating hrp36 mRNA levels (Fig. 1D).

\section{Argonaute-2-null mutants show defects in adult pre-mRNA splicing patterns}

We took advantage of two Ago-2 mutant fly strains to investigate the role Ago-2 has in splicing in adult flies. One strain, Ago-2 ${ }^{51 \mathrm{~B}}$, was an Ago-2-null mutant caused by an imprecise P-element excision that deleted the start 
A
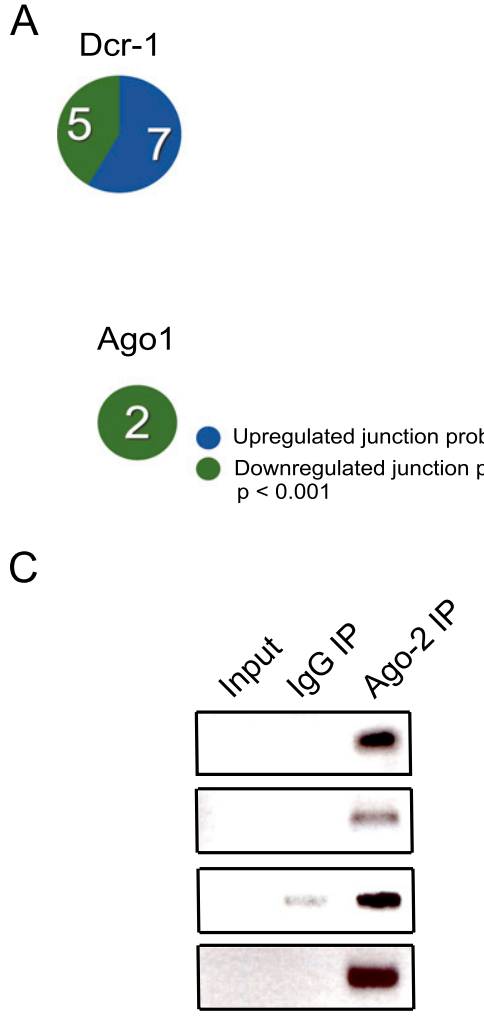

Dcr-2

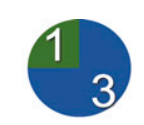

Ago-2

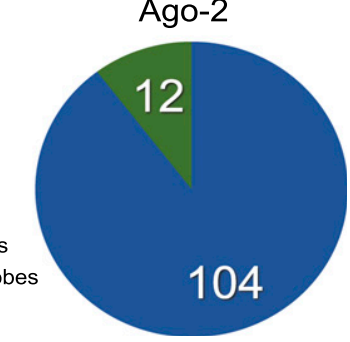

CG8533

CG6686

dco

ppk28
B
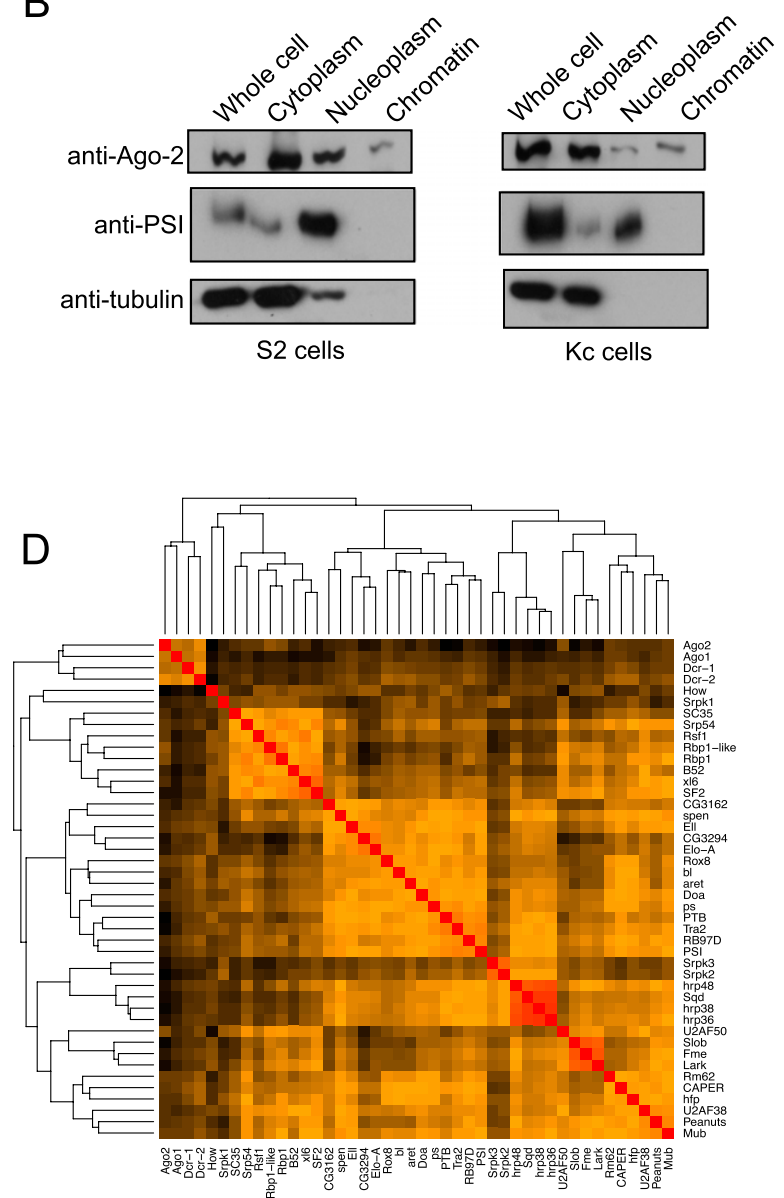

Figure 1. Analysis of Ago-2 in Drosophila cell culture. (A) Splice junction microarray summary. The number of up-regulated and down-regulated junction probes in response to knockdown of each protein is indicated. $(B)$ Subcellular localization of endogenous Ago-2. PSI is used as a nucleoplasmic marker, and tubulin is used as a cytoplasmic marker. Importantly, fractions are not normalized for total protein content and are not meant to imply information about the relative abundance of Ago-2 in each fraction, only on cellular location. $(C)$ RT-PCR of RNA recovered after immunoprecipitation of Ago-2 from S2 nuclear extract. $(D)$ Clustered heat map of Pearson correlation coefficients of global RNA expression levels after knockdown of many RNA-binding proteins.

codons for Ago-2 (Xu et al. 2004). The other, Ago-2 ${ }^{\mathrm{V} 966 \mathrm{M}}$, was a point mutant that is deficient in catalytic slicer activity (Kim et al. 2007). Homozygous Ago-2 ${ }^{51 \mathrm{~B}}$ flies showed no detectable expression of Ago-2 by immunoblotting, while homozygous Ago-2 ${ }^{\mathrm{V} 966 \mathrm{M}}$ flies showed expression of Ago-2 to a level similar to that seen in $\mathrm{w}^{1118}$ control flies (Fig. 2A).

To determine differences in pre-mRNA splicing patterns in the Ago-2 mutant strains, we used highthroughput mRNA sequencing (mRNA-seq) to analyze the mRNA populations present in 0 - to 16 -h posteclosion males from homozygotes and heterozygotes from both strains. After filtering and mapping, we obtained between 58 million and 95 million mapped reads for each strain (Supplemental Fig. 2A). Consistent with the immunoblot data, the level of Ago-2 mRNA transcripts was dramatically reduced in the homozygous Ago-2 ${ }^{51 \mathrm{~B}}$ sample (Supplemental Fig. 2B). We then used JuncBASE to determine the differential splicing patterns present in each sample (Brooks et al. 2011). The percent spliced in $(\Psi)$ value for every splice junction in each sample was computed (Venables et al. 2008). We used the $\Psi$ values for splice junctions in the heterozygous Ago- $2^{51 \mathrm{~B}}$ sample as a reference. We then designated any splice junction whose $\Psi$ value changed by at least 5 as different from the reference sample. Using these criteria, we observed 183,152, and 341 significantly changing splice junctions in the Ago-2 $2^{\mathrm{V} 966 \mathrm{M}}$ heterozygote, Ago- ${ }^{\mathrm{V} 966 \mathrm{M}}$ homozygote, and Ago- $2^{51 \mathrm{~B}}$ homozygote samples, respectively (Fig. 2B). We observed approximately twice as many splicing changes in the homozygous Ago-2 deletion mutant than in any other sample, despite the fact that this sample and the reference sample were siblings. Furthermore, this is consistent with the splice junction microarray data in which many junctions were sensitive to Ago-2 knockdown but only a few splice junctions were sensitive to knockdown of the siRNA-producing enzyme Dcr-2 (Fig. 1A). Importantly, no known splicing factor showed a significant change in RNA expression levels between 


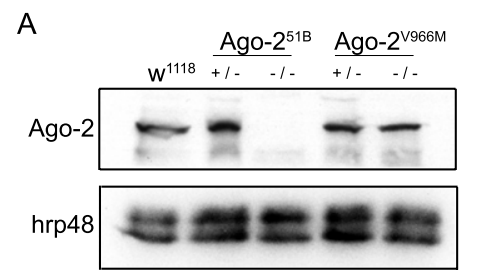

B

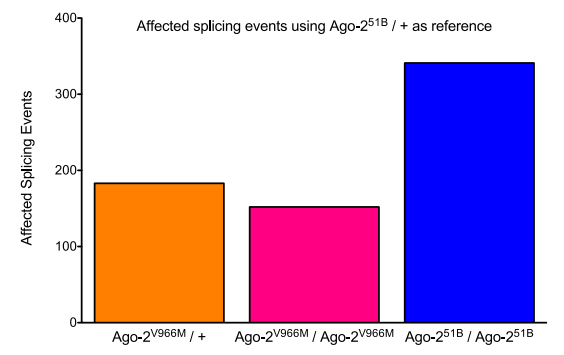

C
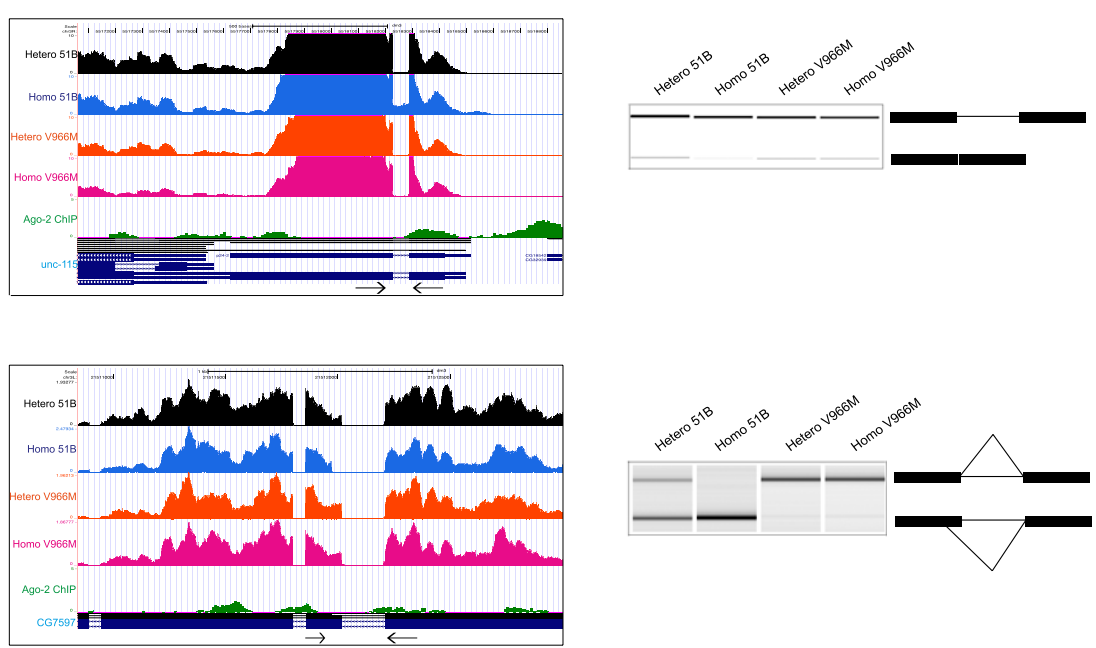

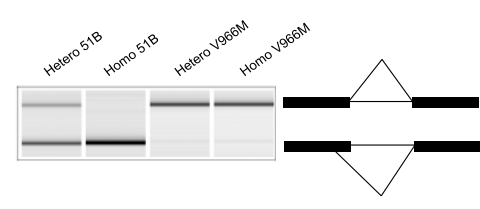

Figure 2. Analysis of splicing events affected in Ago-2 mutant Drosophila adults. (A) Ago-2 immunoblot of whole-fly extracts from Ago-2 mutant strains. Hrp48 was used as a loading control. (B) Number of unique splicing changes, broken down by alternative event type, observed in each Ago-2 mutant strain. $(C)$ Two novel alternative splicing events detected in the homozygous Ago-2 $2^{51 \mathrm{~B}}$ strain and validated by RT-PCR using RNA isolated from 0 - to 16-h post-eclosion adult males. The positions of the primers used to perform the RT-PCR are indicated as black arrows.

any of the four samples (Supplemental Fig. 2C). Selected splicing changes were verified using semiquantitative RT-PCR on RNA collected from adult males of the appropriate genotype (Fig. 2C).

\section{The chromatin association of Argonaute-2 is distinct from its regulation of pre-mRNA splicing}

Recent reports have implicated chromatin structure and the presence of chromatin-associated factors in the regulation of alternative splicing (Batsche et al. 2006; Spies et al. 2009; Luco et al. 2010; Pradeepa et al. 2012), and Argonaute proteins have been known to affect chromatin structure (Buhler and Moazed 2007; Pushpavalli et al. 2012). To address whether a similar mechanism was responsible for the observed Ago-2-mediated splicing changes, we performed chromatin immunoprecipitation (ChIP) coupled with deep sequencing (ChIP-seq) on endogenous Ago-2 in Drosophila S2 cells. The ChIP-seq immunoprecipitations were performed on biological replicates using a previously characterized antibody (Miyoshi et al. 2005) and were specific for the precipitation of Ago-2 (Supplemental Fig. 3A). After filtering for quality, $\sim 20$ million reads mapped uniquely for each experimental replicate (Supplemental Fig. 3B), and there was a high degree of overlap between the replicates (Supplemental Fig. 3C).

Most peaks of Ago-2 chromatin binding occurred at promoters (Fig. 3A). These ChIP-seq data from embryonically derived S2 cells were also compared with ChIPchip data for Ago-2 from larvae that were produced by the modENCODE Consortium (Fig. 3A; Celniker et al. 2009). This comparison showed a high degree of overlap of Ago2-bound genomic regions but also a significant number of differences, possibly indicating the changing occupancy of these regions by Ago-2 during development. Further- more, this promoter enrichment of Ago-2 on chromatin detected by ChIP-seq was even more pronounced when considering only those genes whose mRNA expression levels changed upon Ago-2 RNAi knockdown in the splice junction microarray experiments (Fig. 3B, red). However, genomic positions of Ago-2 chromatin occupancy did not correlate with whether or not splicing of target transcripts was regulated by Ago-2 (Fig. 3B, purple). Therefore, it is unlikely that the splicing changes we observed due to Ago-2 are occurring through siRNAmediated heterochromatin formation (Allo et al. 2009; Ameyar-Zazoua et al. 2012).

Since Ago-2 has no known DNA-binding domains, we reasoned that Ago-2 localization to chromatin may be due to its interaction with one or more recruiting factors. Previous studies had documented a physical interaction between Ago-2 and the chromatin-binding factor CP190 as well as a colocalization on chromatin of Ago-2 with some of the trithorax and Polycomb group (PcG) proteins (Moshkovich et al. 2011). We again used ChIP-chip data from the modENCODE Consortium (Celniker et al. 2009) to compare our observed Ago-2 ChIP data in S2 cells with those of 20 other proteins (Fig. 3C; Supplemental Fig. 3D). Ago-2 binding to chromatin colocalized strongly with the binding of several other factors, including many PcG group genes. We detected the enrichment of several sequence motifs in Ago-2-bound regions, including motifs that closely match the known binding sites for Drosophila CTCF (Supplemental Fig. 3E; Cuddapah et al. 2009).

\section{Argonaute-2 functions in transcriptional repression}

In addition to changes in splicing patterns, many changes in gene expression were observed in the Ago-2 mutant adult male mRNA-seq samples. Generally, there was 

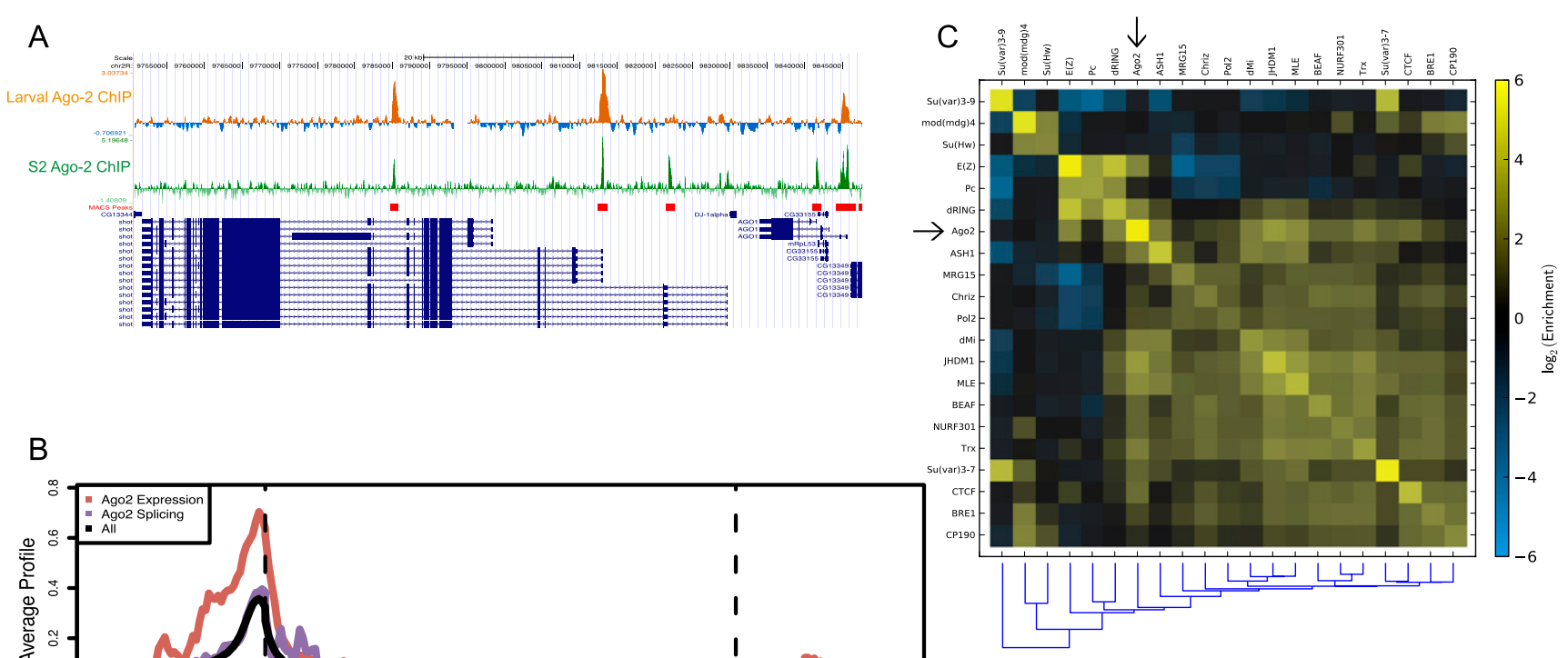

$B$

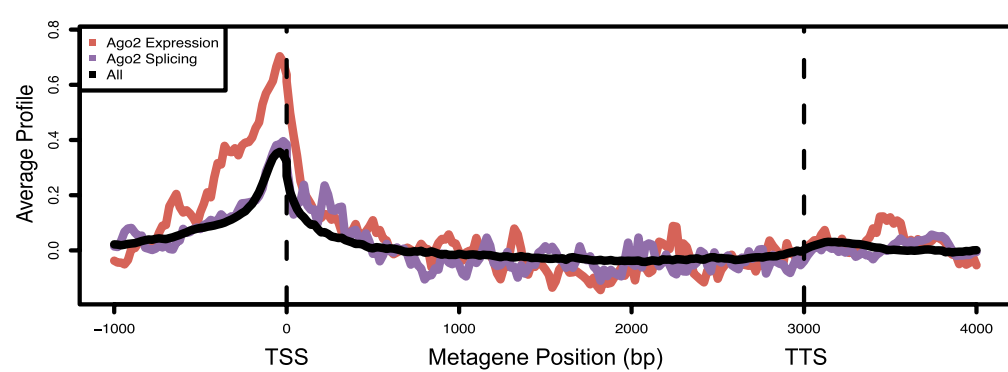

Figure 3. Chromatin association of Ago-2 in Drosophila cell culture. (A) Representative browser graphic of Ago-2 ChIP performed on larvae (orange) and embyronically derived S2 cells (green). (B) Profile of Ago-2 ChIP tag density of all genes (black), genes whose mRNA expression level was sensitive to Ago-2 in S2 cells (red), and Ago-2 splicing targets in S2 cells (purple), represented along a metagene. (C) Clustered heat map showing enrichment of colocalization on chromatin by ChIP-seq and ChIP-chip between 21 different chromatin-binding factors (Celniker et al. 2009).

considerably greater misregulation of RNA expression in the homozygous deletion mutant than in the catalytic mutants (Fig. 4A). This is consistent with the greater misregulation of splicing in the deletion mutant and with the idea of Ago-2 having nuclear roles beyond its catalytic RNA slicer activity (Moshkovich et al. 2011). Consistent with a previous report (Cernilogar et al. 2011), we observed a general up-regulation of heat shock proteins in the homozygous deletion mutant. However, this upregulation did not occur in the homozygous catalytic mutant (Supplemental Fig. 4A).

To determine the genes whose expression was sensitive to the presence of Ago-2 and not to its catalytic activity, we took the following approach: We began with the genes whose FPKM (fragments per kilobase of exon per million reads mapped) values were significantly different between the homozygous and heterozygous deletion mutant samples (Trapnell et al. 2010) and subtracted the genes that also showed significant changes between the homozygous and heterozygous catalytic mutant samples (Supplemental Fig. 4B). To control for the slight differences in genetic background between the two mutants, we then subtracted the genes that showed significant changes between the two heterozygous samples (Supplemental Fig. 4C,E). Finally, if Ago-2 has RNA regulatory roles beyond its catalytic activity, it would be expected to find a high degree of similarity in the patterns produced in the heterozygous deletion mutant and homozygous catalytic mutant because both samples contain "structurally" intact Ago-2. We observed such an overlap containing 483 genes (Fig. 4B; Supplemental Fig. 4D).

Of these 483 genes, 53 of them were among the 968 bound at the chromatin level by Ago-2 in S2 cells. This represents a modest but significant overlap between Ago2-bound genes and those whose expression is sensitive to Ago-2 ( $P$-value $=0.001$, hypergeometric test $)$. Of the 53 bound and regulated genes, RNA levels for 49 of them are greater in the homozygous than the heterozygous Ago-2 deletion mutant (Fig. 4C; Supplemental Fig. 4F,G). Considering that Ago-2 is chromatin-bound at these genes, it is likely that Ago-2 is acting as a transcriptional repressor in these cases.

To address the possibility that the observed increase in RNA levels in the Ago-2-null mutant was due to an increase in RNA stability of these messages and not transcriptional up-regulation, we designed a quantitative RT-PCR (qRT-PCR) experiment. Primer pairs were designed against exon and intronic regions of two putative Ago-2 transcriptional targets and, as a negative control, one nontarget. If the observed increase in RNA levels was due to a stability effect, we would expect to see an increase only in mature mRNA, as seen by exonic amplicons. However, if the increase was due to a transcriptional effect, we would expect an increase in both exonic and intronic amplicons. In comparing the heterozygous and homozygous Ago-2null mutants, we observed such an increase in exonic and intronic regions in homozygotes for two Ago-2 targets but not for the nontarget control (Fig. 4D). Thus, 
A

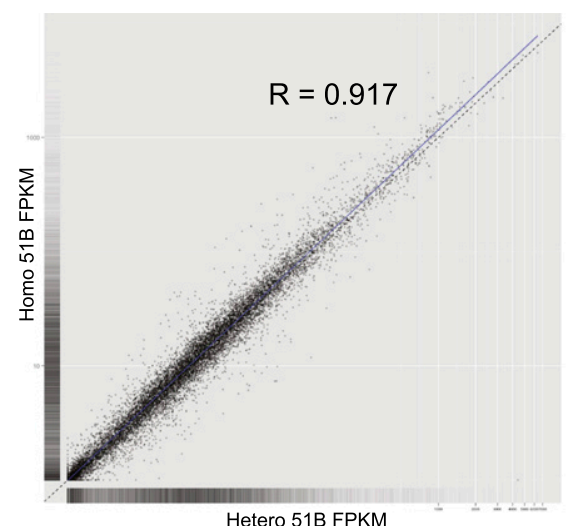

B

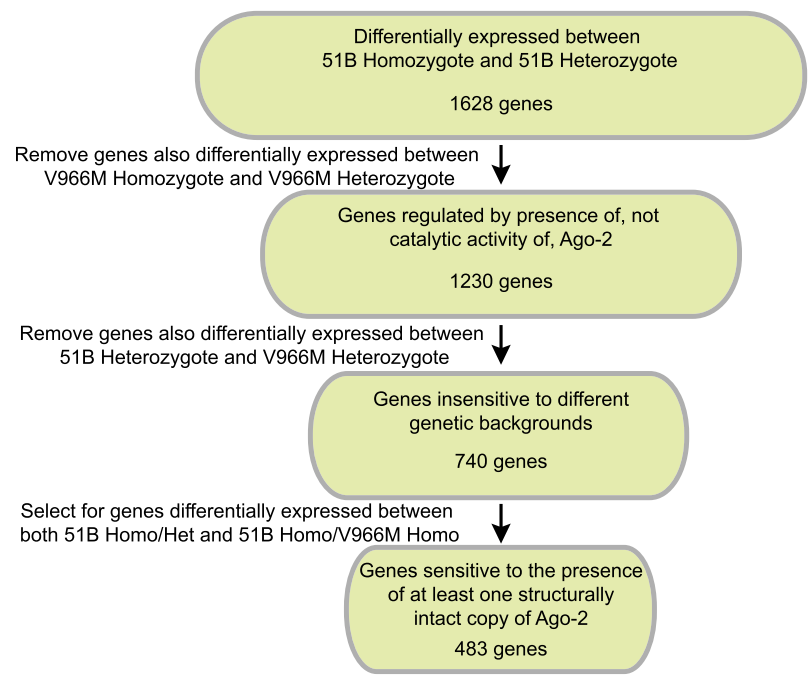

D

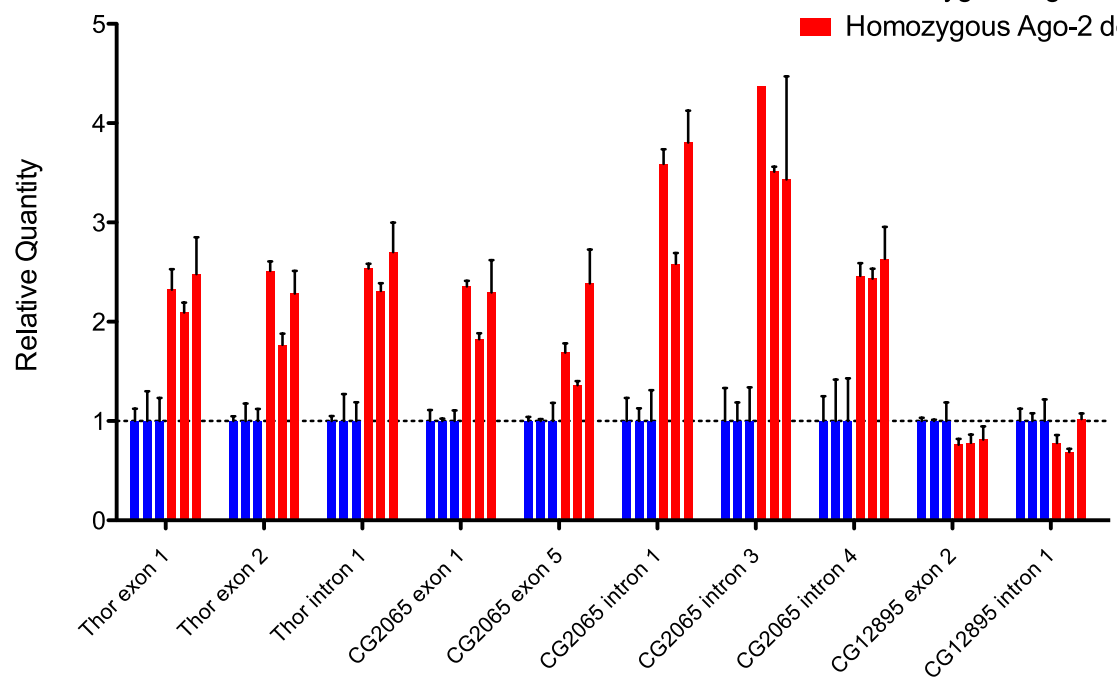

Figure 4. mRNA-seq analysis of Ago-2 mutant strains. (A) Scatter plots of FPKM values of all genes, comparing heterozygotes and homozygotes of Ago-2 deletion mutants $(51 \mathrm{~B}$; left) and catalytic mutants (V966M; right). (B) Strategy to identify genes that are sensitive to the presence of Ago-2 but not to its catalytic activity. $(C)$ mRNA levels of genes that were both sensitive to the presence, but not catalytic activity, of Ago-2 in whole flies and bound by Ago-2 at the chromatin level in S2 cells. Expression levels were normalized against those seen in the heterozygous Ago-2 ${ }^{51 \mathrm{~B}}$ sample. (D) qRT-PCR signals from exonic and intronic amplicons from Ago-2 transcriptional targets. CG12895 was not a transcriptional target of Ago-2 and is a negative control. qRT-PCR signals were measured in technical triplicate for each sample of biological triplicates. Error bars are standard deviations for each technical triplicate set. 
the increase in RNA levels is likely due to a transcriptional effect.

Using the splice junction microarray, we were also able to visualize switching events between alternative promoters upon Ago-2 knockdown. There were cases in which we detected significant Ago-2 chromatin binding centered over one of these alternative promoters (Supplemental Fig. 4H). Additionally, usage of the bound promoter increased upon Ago-2 knockdown. Taken together, these data extend the previously observed Ago-2 chromatin binding to identify a subset of genes whose promoters are bound and repressed by Ago-2, thus implicating Ago-2 directly in transcriptional repression.

\section{Argonaute-2 binds RNA throughout the transcriptome}

To directly determine the RNA molecules bound by Ago- 2 in the Drosophila nucleus, we performed CLIP-seq on UVcross-linked nuclear extract from S2 cells (Licatalosi et al. 2008) using a homemade polyclonal antibody (Supplemental Fig. 5A,B). Importantly, we sequenced premRNAs and mRNAs, not siRNAs, bound to Ago-2, since the vast majority of CLIP tags were between 30 and 40 nucleotides (nt) long. After using randomized barcodes to remove potential PCR duplicates (Konig et al. 2010), we aligned the reads to the repeat-masked Drosophila genome and determined significantly enriched regions of tag density (S Webb, G Kudla, D Tollervey, and S Granneman, in prep.). We identified 837 clusters, of which 811 overlapped with annotated genomic features, with $93 \%$ of those mapping to the mRNA sense strand. The majority of these clusters overlapped with protein-coding genes (Fig. 5A), although we also observed significant overlap with tRNAs and snoRNAs (Supplemental Fig. 5C,D; Taft et al. 2009; Haussecker et al. 2010).

In some cases, we observed overlap between Ago-2 splicing targets identified by the splice junction microarray and Ago-2 CLIP-seq clusters. As an example, we observed a cluster of CLIP tag reads immediately next to the affected cassette exon in the dco gene (Fig. 5B). Overall, Ago-2 splicing targets were enriched 3.1-fold in the set of CLIP-bound genes $(P=0.0005$, Fisher's exact).

We also detected significantly enriched sequence motifs in the clusters, most of which were G-rich (Fig. 5C). This is consistent with a previous report suggesting that mouse Ago-2 may have a specific preference for G-rich motifs, independent of whether it is loaded with a small RNA (Leung et al. 2011). Tags containing the most enriched motif, GGCGG, were likely to have mutations, possible indicators of the site of cross-linking (Hafner et al. 2010; Konig et al. 2010), immediately next to the motif (Fig. 5D). The 25th and 100th most enriched motifs, CCGAT and CAGCC, respectively, showed no such enrichment of mutations. We then created a motif composed of the top four enriched sequences in the CLIP clusters, weighted by their prevalence in the clusters (Supplemental Fig. 5F). This motif was again very G-rich. When we searched for the presence of this motif near splice sites, we detected an enrichment of the motif near Ago-2-sensitive splice sites relative to those splice sites that were insensitive to Ago-2 (Fig. 5E). This enrichment seemed to be contained in the flanking exons and not within the affected intron (Supplemental Fig. 5G).

\section{Discussion}

Although mammalian argonaute proteins are primarily known for their cytoplasmic functions, it has become clear that they can spend at least part of their time in the nucleus (Fig. 1B; Weinmann et al. 2009) and that once in the nucleus, they can perform important functions relevant to chromatin formation and transcriptional silencing (Verdel et al. 2004; Janowski et al. 2006). We have now expanded that nuclear repertoire to Drosophila and shown that it includes direct transcriptional repression and regulation of alternative pre-mRNA splicing.

Previous reports have linked Ago-2 to higher-order chromatin structures, insulator function through interaction with CP190 and CTCF, and transcriptional silencing of heat shock loci through small RNAs in Drosophila (Cernilogar et al. 2011; Moshkovich et al. 2011). Indeed, the studies on the effects of Ago-2 on the heat shock loci used Ago-2-associated small RNAs and suggest a role for Ago-2 in RNA polymerase II pausing or elongation. However, the transcriptional repression that we report here is independent of the catalytic activity of Ago-2 but is related to its chromatin binding. It is unlikely that Ago-2 is directly contacting the DNA to mediate this repression, since Ago-2 has no known DNA-binding domains. Formaldehyde is an efficient protein-protein cross-linker, and perhaps interaction with other proteins is required to mediate association with DNA. Although the enrichment we observed in the ChIP-seq reads was modest, the binding sites are quite consistent with those previously reported (Moshkovich et al. 2011) and can be readily connected to repression of mRNA steady-state levels in Ago-2-null mutants but not in Ago-2 catalytic mutants (Fig. 4D).

If Ago-2 is not directly binding DNA, it is likely colocalizing with other chromatin-associated DNAbinding factors, such as the PcG proteins, as we observed. In fact, previous reports have shown that members of the RNAi machinery are required for proper PcG function in Drosophila cells (Grimaud et al. 2006). The fact that the overwhelming majority of direct transcriptional targets of Ago-2 were repressive events seems to fit nicely with the PcG complex being a repressive chromatin complex (Fig. 4C). In fact, $80 \%$ of these direct transcriptional targets are bound by at least one Polycomb protein in addition to Ago-2 $\left(P=2.3 \times 10^{-7}\right.$, Fisher's exact). This repression may also be developmentally regulated, since the locations of Ago-2 chromatin binding change slightly between embryonically derived S2 cells and larvae.

On average, the level of transcriptional depression that we observed upon loss of Ago-2 was approximately twofold. This level of depression is lower than has been observed upon loss of PcG proteins in other circumstances (Schwartz et al. 2010). However, in other cases, loss of particular PcG complex members has resulted in 


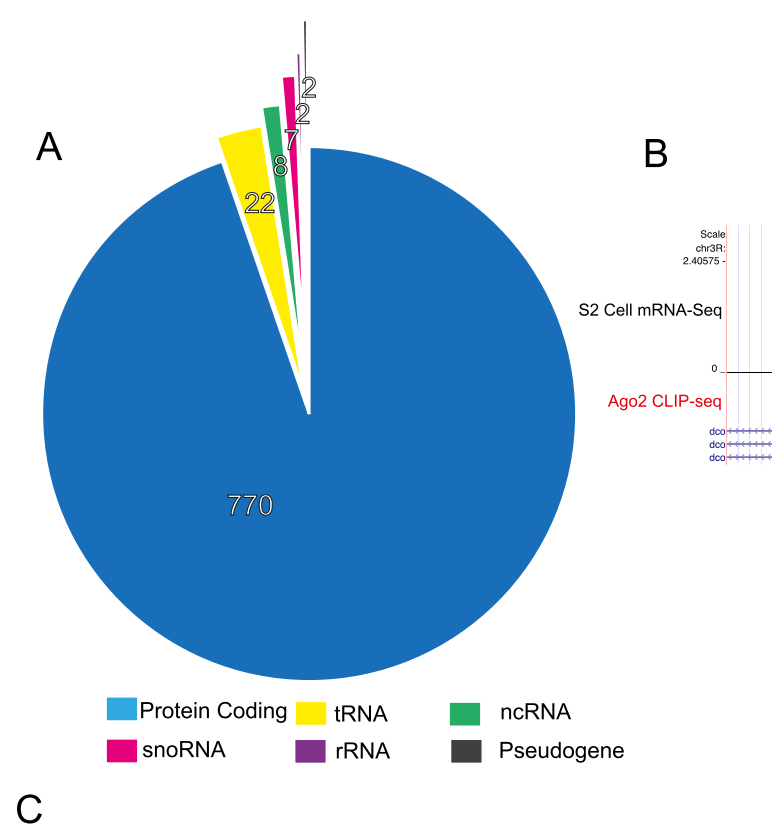

C

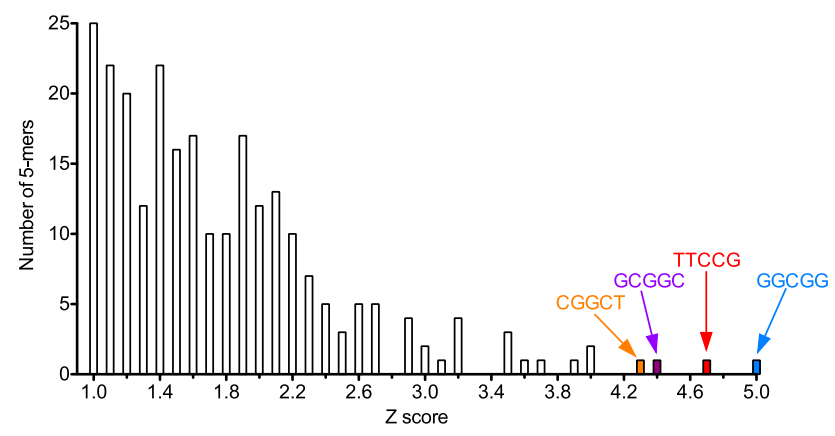

$\mathrm{E}$

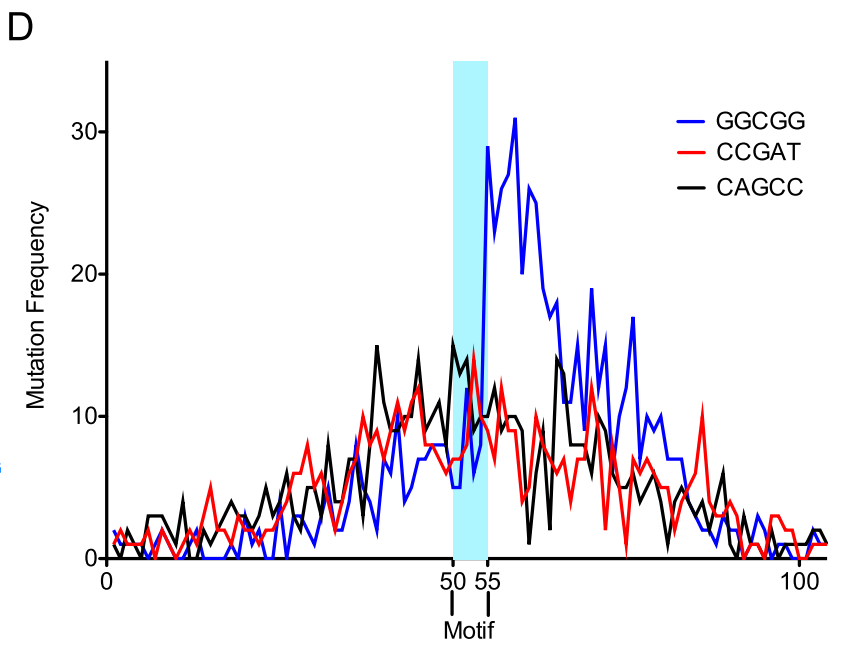

Position (nt)

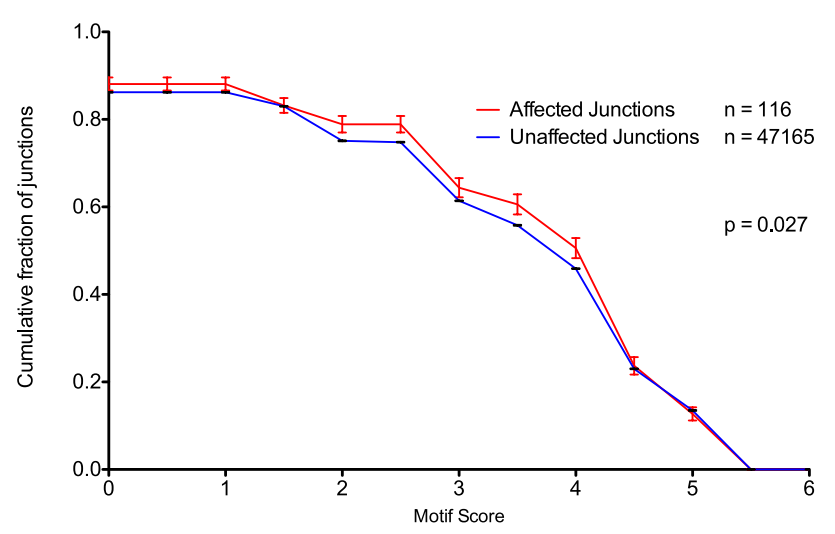

Figure 5. CLIP-seq analysis of Drosophila Ago-2. (A) Pie chart indicating where significantly enriched clusters of Ago-2 binding were found using CLIP-seq. (B) Browser graphic showing S2 cell mRNA expression in black (as determined by the ModEncode Consortium) of the $5^{\prime}$ end of the dco gene. The cassette exon shown was shifted toward exclusion after knockdown of Ago-2. Ago-2 CLIP tags are shown in red. $(C)$ Enriched 5-mers contained in clusters of Ago-2 CLIP tags. The highest enriched motifs are shown. (D) Mutation density around enriched motifs in Ago-2 CLIP tag clusters. The frequency of mutations in $50 \mathrm{nt}$ upstream of and downstream from the motif were calculated for the most enriched (blue), 25th most enriched (red), and 100th most enriched (black) motifs. (E) Enrichment of the G-rich motif obtained from the CLIP-seq experiment around Ago-2-sensitive splice junctions. Sequences were restricted to $200 \mathrm{nt}$ into the exon and $50 \mathrm{nt}$ into the intron surrounding the $5^{\prime}$ and $3^{\prime}$ splice sites of Ago-2-sensitive (red) or Ago-2-insensitive (blue) junctions. 
a similar, modest derepression of PcG target genes (Endoh et al. 2008).

Importantly, the genes that show Ago-2 chromatin association events do not correlate with the target transcripts whose pre-mRNA splicing is affected upon RNAi knockdown of Ago-2. Therefore, the splicing effects we observed are likely unrelated to the Ago-2 association with chromatin in mammals, where the formation of heterochromatin mediated by siRNAs is thought to slow RNA polymerase II and affect alternate splicing events (Allo et al. 2009; Ameyar-Zazoua et al. 2012). Moreover, in mammals, the effects of Ago-2 also require Dicer, which is not the case in Drosophila, since Dicer-1 and Dicer-2 RNAi knockdown shows no effects on premRNA splicing. Instead, out data point to a more direct role of Ago-2 in the splicing changes that we observed and that are strongly supported by the direct RNA binding by Ago-2 from our CLIP data, suggesting that the observed changes in pre-mRNA are due to Ago-2 binding of premRNA and not chromatin, since no Ago-2 ChIP-seq peaks are found on the pre-mRNA splicing target genes. Furthermore, it is unlikely that splicing changes that occur upon Ago-2 knockdown are happening indirectly through a change in expression of another splicing factor, as neither the array experiments nor mRNA-seq experiments showed significant changes in mRNA transcripts encoding splicing factors, although it should be pointed out that mRNA levels, not protein levels, were measured.

Small RNAs affecting splicing patterns have been reported (Kishore and Stamm 2006; Kishore et al. 2010). In particular, snoRNAs have been implicated in changing alternative splicing outcomes. We observed Ago-2 strongly binding to several snoRNAs in our CLIP assays, indicating one potential mechanism for the action of Ago-2 on alternative splicing.

Although we were able to observe a general enrichment for CLIP clusters near splice sites regulated by Ago-2 (Fig. 5E), we were unable to definitively link the position of Ago-2 binding relative to a splice site to either positive or negative regulation of that splice site. The enrichment of the G-rich motif within CLIP clusters was relatively modest. We speculate that this may be at least partially due to the detection of a mixture of Ago-2-binding events, many of which are driven by a vast array of different small RNAs.

We also observed Ago-2 binding to long stretches of RNA across many gene transcripts in CLIP-seq assays. This was qualitatively different from what has been reported for the binding patterns for other splicing factors (Huelga et al. 2012). Although bound genes were enriched for being more highly expressed (Supplemental Fig. 5E), many highly expressed genes were not bound at all, and control CLIP experiments did not yield the same extended patterns of binding. These findings suggest that the observed extended binding of Ago-2 across many transcripts may be legitimate. Further experimental work will be needed to determine the significance of this observation as well as a unified mechanism for the action of Ago-2 on alternative splicing and its interactions with other splicing factors and spliceosome components.

\section{Materials and methods}

\section{RNAi and splice junction microarrays}

S2 cells were treated with 400-base-pair (bp) dsRNA targeting each protein for $4 \mathrm{~d}$. dsRNA molecules were designed using SnapDragon (http://www.flyrnai.org/cgi-bin/RNAi_find_primers.pl) to minimize potential off-target effects. After 4 d, total RNA was recovered. Knockdown efficiencies were monitored by Western blotting (Supplemental Fig. 1A).

For each microarray hybridization, $1 \mu \mathrm{g}$ of total RNA from the experimental knockdown and $1 \mu \mathrm{g}$ of total RNA from a nonspecific knockdown were amplified and converted to aRNA using the MessageAmp II aRNA Amplification kit following the manufacturer's recommendations (Ambion) and labeled with Cy5 and Cy3 monoreactive dye, respectively (GE Healthcare). The custom splicing-sensitive microarray used was based on FlyBase version 5.15 and interrogated 48,550 annotated splicing events from 11,368 different genes with three overlapping 36-nt oligonucleotide probes: one probe centered at the splice junction, and two probes offset by $3 \mathrm{nt}$ on each side of the splice junction. In addition, one fully exonic probe per $100 \mathrm{nt}$ of each mRNA, on average, was added. The 389,068 different probes were distributed randomly onto custom Agilent $500 \mathrm{~K}$ arrays and used for hybridization of each cDNA sample. The microarrays were then processed and scanned following the manufacturer's recommendations (Agilent Technologies). The feature extraction reports were loaded into $\mathrm{R}$ (http:// www.r-project.org) and Lowess-normalized using the marray package (Gentleman et al. 2004; Smyth 2004). The genes with affected alternative splicing were first identified using ANOVA, comparing the group of exonic probes common to all transcripts with the different groups of splice junction probes corresponding to every splicing event of a given gene. The genes with $Q$-values $<0.001$ (adjusted using BenjaminiHocheberg correction) were then subjected to $t$-tests to identify the group of junction probes significantly affected with a $P$-value of $<0.001$.

To determine the degree of overlap in regulation between RNA-binding proteins, Pearson correlations of the net expression of all genes were compared after RNAi knockdown of each protein.

RNA immunoprecipitation (RIP) of predicted Ago-2 target pre-mRNAs

Endogenous Ago-2 protein was immunoprecipitated from S2 nuclear RNP-enriched extracts that were cross-linked with $0.05 \%$ formaldehyde (Pinol-Roma et al. 1990). The extracts were stored in HNEB2 (10 mM HEPES-KOH at pH 7.6, $100 \mathrm{mM} \mathrm{KCl,}$ $2.5 \mathrm{mM} \mathrm{MgCl} 2,0.2 \% \mathrm{NP}-40,0.2 \mathrm{mM}$ PMSF). Nine-hundred microliters of extract was incubated with protein A Dynabeads (Invitrogen) that had been preincubated with monoclonal antiAgo-2 antibody (Miyoshi et al. 2005). As a control, an immunoprecipitation using protein A Dynabeads preincubated with IgG was also done. The reaction was incubated for $4 \mathrm{~h}$ at $4^{\circ} \mathrm{C}$. The beads were then washed four times with $1 \mathrm{~mL}$ of wash buffer (20 mM HEPES at $\mathrm{pH} 7.6,500 \mathrm{mM} \mathrm{KCl}, 5 \mathrm{mM} \mathrm{MgCl}_{2}$, $0.5 \mathrm{mM}$ PMSF, $50 \mathrm{U} / \mathrm{mL}$ RNasin [Promega]). The beads were then resuspended in $100 \mu \mathrm{L}$ of $1 \times \mathrm{RQ} 1$ DNase buffer (Promega). Five units of RQ1 DNase I (Promega) was then added, and the reaction was incubated for $1 \mathrm{~h}$ at $37^{\circ} \mathrm{C}$. Cross-links were reversed by adding EDTA to $20 \mathrm{mM}$ and incubating for $1 \mathrm{~h}$ at $65^{\circ} \mathrm{C}$. RNA was then eluted by phenol/chloroform-extracting the beads and ethanol-precipitating. The pellet was washed twice with $1 \mathrm{~mL}$ of $70 \%$ ethanol and resuspended in $15 \mu \mathrm{L}$ of water. 
RNA concentration was measured using a NanoDrop spectrophotometer. Equal amounts of Ago-2 and IgG-immunoprecipitated RNA and RNA isolated from the starting RNP-enriched extracts were then used for RT-PCR using random hexamers. Individual bound transcripts were then assayed using HotStart PCR (Qiagen) and gene-specific primers.

\section{mRNA-seq from adult files}

Total RNA was collected by Trizol extraction from five 0 - to 16-h post-eclosion male adult files. RNA was collected from homozygotes and heterozygotes from the following strains: $\mathrm{w}^{1118} ;+$; Ago-2 V966M/TM3,twi-GFP,Sb,Ser and yw; +; Ago- $2^{51 \mathrm{~B}} / \mathrm{TM} 3$, Ser, $\mathrm{y}^{+}$. Poly $\mathrm{A}^{+}$RNA was then selected twice by incubating $10 \mu \mathrm{g}$ of RNA with oligo-dT Dynabeads (Invitrogen). Starting with $200 \mathrm{ng}$ of poly $\mathrm{A}^{+} \mathrm{RNA}$, then, mRNA-seq libraries were made by first chemically fragmenting the RNA (Ambion, AM8740) and constructing a library using the NEBNext mRNA Library Prep Reagent set for Illumina (New England Biolabs, E6100S). Duplicate libraries were made from separate RNA preps. Samples were barcoded and sequenced using 50-bp single-end sequencing on an Illumina HiSeq2000. Reads were demultiplexed and aligned to the Drosophila genome using TopHat 1.4.0 (Trapnell et al. 2009) and the following options: -a 6 -i 40 -coverage-search -butterflysearch -segment-mismatches 2 . We obtained between 58 million and 97 million reads for each sample, and $\sim 97 \%$ of those reads mapped uniquely. Of those reads, $\sim 5 \%$ crossed known splice junctions.

Transcript abundances were then calculated using Cufflinks (Trapnell et al. 2010) and the following options: -u -m $280-\mathrm{N}$ -min-intron-length 40. Output from Cufflinks and Cuffdiff was visualized using cummeRbund (http://compbio.mit.edu/ cummeRbund/index.html).

Alternative splicing analysis from RNA-seq data was performed using JuncBASE (Brooks et al. 2011). Briefly, $\Psi$ values were calculated for each splice junction in each sample using both reads that crossed splice junctions and exonic reads that were specific to one particular outcome of a splicing event. The heterozygous Ago- $2^{51 \mathrm{~B}}$ sample was designated as the reference sample. $\Psi$ values in a particular sample that deviated from the reference $\Psi$ value by at least 5 were then marked as significantly changing events.

\section{$q R T-P C R$}

Primers were designed against intronic and exonic regions of two transcripts found to be both up-regulated in Ago-2-null mutants and bound by Ago-2 by ChIP-seq. As a control, another transcript was selected that was not up-regulated in the null mutants. qRT-PCR was performed on total RNA isolated from heterozygous and homozygous null mutants using an Applied Biosystems ViiA 7 qPCR machine. Reverse transcription was performed using SuperScript III (Invitrogen) and random hexamer primers. Ten-microliter PCR reactions contained $5 \mu \mathrm{L}$ of $2 \times$ SYBR Green master mix (Applied Biosystems), $4 \mu \mathrm{L}$ of cDNA, and $1 \mu \mathrm{L}$ of $1 \mu \mathrm{M}$ primers. Experiments were performed in technical triplicate on each replicate of biological triplicates. RNA levels were normalized to the levels of Rp49 in each sample.

\section{Ago-2 ChIP-seq}

Briefly, S2 cells were cross-linked with $2 \%$ formaldehyde for 1 min. The remaining formaldehyde was then quenched with 250 $\mathrm{mM}$ glycine (pH 8.0). Cells were then lysed in SDS and sonicated using a Covaris sonicator. Ago-2 was then immunoprecipitated using a monoclonal antibody (Miyoshi et al. 2005) bound to protein A Dynabeads (Invitrogen), washed very stringently, and eluted using SDS. Cross-links were then reversed by incubating overnight at $65^{\circ} \mathrm{C}$, and libraries were made from immunoprecipitated DNA using the New England Biolabs ChIP-Seq Sample Prep Reagent kit (New England Biolabs, E6200S). Samples were barcoded and sequenced using 50-bp single-end sequencing on an Illumina HiSeq2000. As controls, libraries made from input and IgG samples were also made and sequenced. Reads were demultiplexed and aligned to the Drosophila genome using Bowtie 0.12.7 (Langmead et al. 2009). We obtained between 14 million and 28 million reads for each sample, of which between $72 \%$ and $91 \%$ mapped uniquely. Enriched peaks of chromatin binding were determined using model-based analysis of ChIP-seq (MACS) (Zhang et al. 2008).

To compare Ago-2 binding with that of other factors, ChIPchp and ChIP-seq data were retrieved from the modEncode depository (http://modencode.org; Celniker et al. 2009). To determine the degree of overlap between binding regions of each protein, bound regions, as determined by the modEncode Consortium, for a particular protein were compared with both bound regions for every other protein and samples in which the bound regions for every protein had been randomized. The degree of enrichment of colocalization for two proteins was then calculated as the number of base pair overlap between Protein A and Protein B divided by the number of base pair overlap between randomized bound regions of Protein A and randomized bound regions of Protein B. To determine enriched motifs under Ago-2binding sites, we used the HOMER software package (Heinz et al. 2010). To determine the location of Ago-2-binding peaks in relation to annotated genes, the CEAS package was used (Shin et al. 2009).

\section{Ago-2 CLIP-seq}

CLIP-seq on S2 nuclear extract was performed as an adaptation of the iCLIP procedure (Konig et al. 2010, 2011). S2 cells were irradiated three times with $400 \mathrm{~mJ} / \mathrm{cm}^{2} \mathrm{UV}$ at $254 \mathrm{~nm}$. Nuclei were then collected by swelling the cells in hypotonic buffer, douncing, and centrifuging. The nuclei were then resuspended in lysis buffer (50 mM HEPES-KOH at $\mathrm{pH} 7.6,100 \mathrm{mM} \mathrm{NaCl}$, $0.5 \mathrm{mM}$ EDTA) and sonicated six times for $30 \mathrm{sec}$ each using a tip sonicator; Triton X-100 was then added to $1 \%$, and NP-40 was added to $0.1 \%$.

Extracts were treated with DNase I and varying amounts of RNase I (Ambion, AM2295), and then Ago-2 was immunoprecipitated using a homemade polyclonal antibody bound to protein A Dynabeads (Invitrogen). RNA from immunoprecipitated complexes was dephosphorylated on the beads using PNK (New England Biolabs), and an RNA linker was ligated to the $3^{\prime}$ end of the immunoprecipitated RNA using T4 RNA ligase (New England Biolabs). The $5^{\prime}$ end of the RNA was then phosphorylated with ${ }^{32}$ P-ATP using PNK (New England Biolabs), and the complexes were eluted from the beads and run on an SDS-PAGE gel. The gel was exposed to film, and slices of the gel corresponding to the known mobility of Ago- $+15 \mathrm{kDa}$ were excised. Complexes were electroeluted from the gel at $200 \mathrm{~V}$ for $3 \mathrm{~h}$. The complexes were then proteinase K-treated, and RNA was recovered by ethanol precipitation. Reverse transcription was performed using oligos that contained both a multiplexing barcode and a 5-nt random barcode that would allow determination of PCR amplification events. After reverse transcription, the resulting cDNA was gel-purified on a 6\% TBE-urea gel, circularized using Circligase II (Epicentre), and restrictiondigested using BamHI to leave single-stranded cDNA with known sequences on both ends of the insert. The cDNA was 
then amplified using Illumina primers PE 1.01 and PE 2.01 for 25 cycles using Phusion polymerase (New England Biolabs). CLIP libraries were then sequenced using 50-bp single-end sequencing on an Illumina HiSeq.

After demultiplexing and collapsing all potential PCR duplicates, we obtained between 1.7 million and 4.2 million reads for each sample. Of these, between 1.0 million and 2.8 million aligned to the Drosophila genome using Bowtie (Langmead et al. 2009), allowing three mismatches (options -5 9 -v 3 -S), but only between 225,000 and 622,000 aligned uniquely. Many mapped to chrUextra, which contains scaffolds of repeats that are unable to be assembled into the genome.

Clusters were determined using pyCRAC software (S Webb, G Kudla, D Tollervey, and S Granneman, in prep.). Clusters were required to contain at least eight overlapping tags, and at least $1 \mathrm{nt}$ in each cluster was required to be mutated in at least $20 \%$ of tags in the cluster.

Comparisons with S2 cell mRNA-seq data were made by retrieving SAM files from the modENCODE Consortium (Celniker et al. 2009) and analyzing them using Cufflinks (Trapnell et al. 2010) and the following options: -u -m 200 -N -minintron-length 40.

\section{Acknowledgments}

We thank M. Siomi for a generous supply of the anti-Drosophila Ago-2 monoclonal antibody. We thank A. Brooks and N. Alvarez for helpful comments and discussion. We thank V. Hilgers for help in designing and performing the qRT-PCR experiment. This work was supported by NIH grants GM61987, GM097352-01A1, and GM094890-01. J.M.T. was supported by a University of California Cancer Research Coordinating Committee graduate fellowship.

\section{References}

Allo M, Buggiano V, Fededa JP, Petrillo E, Schor I, de la Mata M, Agirre E, Plass M, Eyras E, Elela SA, et al. 2009. Control of alternative splicing through siRNA-mediated transcriptional gene silencing. Nat Struct Mol Biol 16: 717-724.

Ameyar-Zazoua M, Rachez C, Souidi M, Robin P, Fritsch L, Young R, Morozova N, Fenouil R, Descostes N, Andrau JC, et al. 2012. Argonaute proteins couple chromatin silencing to alternative splicing. Nat Struct Mol Biol 19: 998-1004.

Batsche E, Yaniv M, Muchardt C. 2006. The human SWI/SNF subunit Brm is a regulator of alternative splicing. Nat Struct Mol Biol 13: 22-29.

Blanchette M, Green RE, Brenner SE, Rio DC. 2005. Global analysis of positive and negative pre-mRNA splicing regulators in Drosophila. Genes Dev 19: 1306-1314.

Blanchette M, Green RE, MacArthur S, Brooks AN, Brenner SE, Eisen MB, Rio DC. 2009. Genome-wide analysis of alternative pre-mRNA splicing and RNA-binding specificities of the Drosophila hnRNP A/B family members. Mol Cell 33: 438-449.

Brooks AN, Yang L, Duff MO, Hansen KD, Park JW, Dudoit S, Brenner SE, Graveley BR. 2011. Conservation of an RNA regulatory map between Drosophila and mammals. Genome Res 21: 193-202.

Buhler M, Moazed D. 2007. Transcription and RNAi in heterochromatic gene silencing. Nat Struct Mol Biol 14: 10411048.

Celniker SE, Dillon LA, Gerstein MB, Gunsalus KC, Henikoff S, Karpen GH, Kellis M, Lai EC, Lieb JD, MacAlpine DM, et al. 2009. Unlocking the secrets of the genome. Nature 459: $927-$ 930.
Cernilogar FM, Onorati MC, Kothe GO, Burroughs AM, Parsi KM, Breiling A, Lo Sardo F, Saxena A, Miyoshi K, Siomi H, et al. 2011. Chromatin-associated RNA interference components contribute to transcriptional regulation in Drosophila. Nature 480: 391-395.

Chi SW, Zang JB, Mele A, Darnell RB. 2009. Argonaute HITSCLIP decodes microRNA-mRNA interaction maps. Nature 460: 479-486.

Cuddapah S, Jothi R, Schones DE, Roh TY, Cui K, Zhao K. 2009. Global analysis of the insulator binding protein CTCF in chromatin barrier regions reveals demarcation of active and repressive domains. Genome Res 19: 2432.

Czech B, Malone CD, Zhou R, Stark A, Schlingeheyde C, Dus M, Perrimon N, Kellis M, Wohlschlegel JA, Sachidanandam $\mathrm{R}$, et al. 2008. An endogenous small interfering RNA pathway in Drosophila. Nature 453: 798-802.

Endoh M, Endo TA, Endoh T, Fujimura Y, Ohara O, Toyoda T, Otte AP, Okano M, Brockdorff N, Vidal M, et al. 2008. Polycomb group proteins Ring1A/B are functionally linked to the core transcriptional regulatory circuitry to maintain ES cell identity. Development 135: 1513-1524.

Forstemann K, Horwich MD, Wee L, Tomari Y, Zamore PD. 2007. Drosophila microRNAs are sorted into functionally distinct argonaute complexes after production by dicer-1. Cell 130: 287-297.

Gentleman RC, Carey VJ, Bates DM, Bolstad B, Dettling M, Dudoit S, Ellis B, Gautier L, Ge Y, Gentry J, et al. 2004. Bioconductor: Open software development for computational biology and bioinformatics. Genome Biol 5: R80.

Grimaud C, Bantignies F, Pal-Bhadra M, Ghana P, Bhadra U, Cavalli G. 2006. RNAi components are required for nuclear clustering of Polycomb group response elements. Cell 124: 957-971.

Hafner M, Landthaler M, Burger L, Khorshid M, Hausser J, Berninger P, Rothballer A, Ascano M Jr, Jungkamp AC, Munschauer M, et al. 2010. Transcriptome-wide identification of RNA-binding protein and microRNA target sites by PAR-CLIP. Cell 141: 129-141.

Haussecker D, Huang Y, Lau A, Parameswaran P, Fire AZ, Kay MA. 2010. Human tRNA-derived small RNAs in the global regulation of RNA silencing. RNA 16: 673-695.

Heinz S, Benner C, Spann N, Bertolino E, Lin YC, Laslo P, Cheng JX, Murre C, Singh H, Glass CK. 2010. Simple combinations of lineage-determining transcription factors prime cis-regulatory elements required for macrophage and B cell identities. Mol Cell 38: 576-589.

Hua Y, Sahashi K, Hung G, Rigo F, Passini MA, Bennett CF, Krainer AR. 2010. Antisense correction of SMN2 splicing in the CNS rescues necrosis in a type III SMA mouse model. Genes Dev 24: 1634-1644.

Hua Y, Sahashi K, Rigo F, Hung G, Horev G, Bennett CF, Krainer AR. 2011. Peripheral SMN restoration is essential for longterm rescue of a severe spinal muscular atrophy mouse model. Nature 478: 123-126.

Huelga SC, Vu AQ, Arnold JD, Liang TY, Liu PP, Yan BY, Donohue JP, Shiue L, Hoon S, Brenner S, et al. 2012. Integrative genome-wide analysis reveals cooperative regulation of alternative splicing by hnRNP proteins. Cell Rep 1: 167-178.

Janowski BA, Huffman KE, Schwartz JC, Ram R, Nordsell R, Shames DS, Minna JD, Corey DR. 2006. Involvement of AGO1 and AGO2 in mammalian transcriptional silencing. Nat Struct Mol Biol 13: 787-792.

Kawamura Y, Saito K, Kin T, Ono Y, Asai K, Sunohara T, Okada TN, Siomi MC, Siomi H. 2008. Drosophila endogenous 
small RNAs bind to Argonaute 2 in somatic cells. Nature 453: 793-797.

Kim K, Lee YS, Carthew RW. 2007. Conversion of pre-RISC to holo-RISC by Ago2 during assembly of RNAi complexes. RNA 13: 22-29.

Kishore S, Stamm S. 2006. The snoRNA HBII-52 regulates alternative splicing of the serotonin receptor 2C. Science 311: 230-232.

Kishore S, Khanna A, Zhang Z, Hui J, Balwierz PJ, Stefan M, Beach C, Nicholls RD, Zavolan M, Stamm S. 2010. The snoRNA MBII-52 (SNORD 115) is processed into smaller RNAs and regulates alternative splicing. Hum Mol Genet 19: 1153-1164.

Konig J, Zarnack K, Rot G, Curk T, Kayikci M, Zupan B, Turner DJ, Luscombe NM, Ule J. 2010. iCLIP reveals the function of hnRNP particles in splicing at individual nucleotide resolution. Nat Struct Mol Biol 17: 909-915.

Konig J, Zarnack K, Rot G, Curk T, Kayikci M, Zupan B, Turner DJ, Luscombe NM, Ule J. 2011. iCLIP-transcriptome-wide mapping of protein-RNA interactions with individual nucleotide resolution. J Vis Exp 2011: 2638.

Langmead B, Trapnell C, Pop M, Salzberg SL. 2009. Ultrafast and memory-efficient alignment of short DNA sequences to the human genome. Genome Biol 10: R25.

Lee RC, Feinbaum RL, Ambros V. 1993. The C. elegans heterochronic gene lin- 4 encodes small RNAs with antisense complementarity to lin-14. Cell 75: 843-854.

Leung AK, Young AG, Bhutkar A, Zheng GX, Bosson AD, Nielsen CB, Sharp PA. 2011. Genome-wide identification of Ago2 binding sites from mouse embryonic stem cells with and without mature microRNAs. Nat Struct Mol Biol 18: 237-244.

Licatalosi DD, Mele A, Fak JJ, Ule J, Kayikci M, Chi SW, Clark TA, Schweitzer AC, Blume JE, Wang X, et al. 2008. HITSCLIP yields genome-wide insights into brain alternative RNA processing. Nature 456: 464-469.

Luco RF, Pan Q, Tominaga K, Blencowe BJ, Pereira-Smith OM, Misteli T. 2010. Regulation of alternative splicing by histone modifications. Science 327: 996-1000.

Miyoshi K, Tsukumo H, Nagami T, Siomi H, Siomi MC. 2005. Slicer function of Drosophila Argonautes and its involvement in RISC formation. Genes Dev 19: 2837-2848.

Moshkovich N, Nisha P, Boyle PJ, Thompson BA, Dale RK, Lei EP. 2011. RNAi-independent role for Argonaute2 in CTCF/ CP190 chromatin insulator function. Genes Dev 25: 16861701.

Pinol-Roma S, Swanson MS, Matunis MJ, Dreyfuss G. 1990. Purification and characterization of proteins of heterogeneous nuclear ribonucleoprotein complexes by affinity chromatography. Methods Enzymol 181: 326-331.

Pradeepa MM, Sutherland HG, Ule J, Grimes GR, Bickmore WA. 2012. Psip1/Ledgf p52 binds methylated histone H3K36 and splicing factors and contributes to the regulation of alternative splicing. PLoS Genet 8: e1002717.

Pushpavalli SN, Bag I, Pal-Bhadra M, Bhadra U. 2012. Drosophila Argonaute-1 is critical for transcriptional cosuppression and heterochromatin formation. Chromosome Res 20: 333351.

Schwartz YB, Kahn TG, Stenberg P, Ohno K, Bourgon R, Pirrotta V. 2010. Alternative epigenetic chromatin states of polycomb target genes. PLoS Genet 6: e1000805.

Shin H, Liu T, Manrai AK, Liu XS. 2009. CEAS: Cis-regulatory element annotation system. Bioinformatics 25: 2605-2606.

Smyth GK. 2004. Linear models and empirical bayes methods for assessing differential expression in microarray experiments. Stat Appl Genet Mol Biol 3: Article 3.
Spies N, Nielsen CB, Padgett RA, Burge CB. 2009. Biased chromatin signatures around polyadenylation sites and exons. Mol Cell 36: 245-254.

Taft RJ, Glazov EA, Lassmann T, Hayashizaki Y, Carninci P, Mattick JS. 2009. Small RNAs derived from snoRNAs. RNA 15: $1233-1240$.

Taliaferro JM, Alvarez N, Green RE, Blanchette M, Rio DC. 2011. Evolution of a tissue-specific splicing network. Genes Dev 25: 608-620.

Tomari Y, Du T, Zamore PD. 2007. Sorting of Drosophila small silencing RNAs. Cell 130: 299-308.

Trapnell C, Pachter L, Salzberg SL. 2009. TopHat: Discovering splice junctions with RNA-seq. Bioinformatics 25: 11051111.

Trapnell C, Williams BA, Pertea G, Mortazavi A, Kwan G, van Baren MJ, Salzberg SL, Wold BJ, Pachter L. 2010. Transcript assembly and quantification by RNA-seq reveals unannotated transcripts and isoform switching during cell differentiation. Nat Biotechnol 28: 511-515.

Venables JP, Klinck R, Bramard A, Inkel L, Dufresne-Martin G, Koh C, Gervais-Bird J, Lapointe E, Froehlich U, Durand M, et al. 2008. Identification of alternative splicing markers for breast cancer. Cancer Res 68: 9525-9531.

Verdel A, Jia S, Gerber S, Sugiyama T, Gygi S, Grewal SI, Moazed D. 2004. RNAi-mediated targeting of heterochromatin by the RITS complex. Science 303: 672-676.

Weinmann L, Hock J, Ivacevic T, Ohrt T, Mutze J, Schwille P, Kremmer E, Benes V, Urlaub H, Meister G. 2009. Importin 8 is a gene silencing factor that targets argonaute proteins to distinct mRNAs. Cell 136: 496-507.

Wightman B, Ha I, Ruvkun G. 1993. Posttranscriptional regulation of the heterochronic gene lin-14 by lin- 4 mediates temporal pattern formation in C. elegans. Cell 75: 855-862.

Xu K, Bogert BA, Li W, Su K, Lee A, Gao FB. 2004. The fragile $\mathrm{X}$-related gene affects the crawling behavior of Drosophila larvae by regulating the mRNA level of the DEG/ENaC protein pickpocket1. Curr Biol 14: 1025-1034.

Zhang Y, Liu T, Meyer CA, Eeckhoute J, Johnson DS, Bernstein BE, Nusbaum C, Myers RM, Brown M, Li W, et al. 2008. Model-based analysis of ChIP-seq (MACS). Genome Biol 9: R137.

Zhou R, Hotta I, Denli AM, Hong P, Perrimon N, Hannon GJ. 2008. Comparative analysis of argonaute-dependent small RNA pathways in Drosophila. Mol Cell 32: 592-599.

Zisoulis DG, Lovci MT, Wilbert ML, Hutt KR, Liang TY, Pasquinelli AE, Yeo GW. 2010. Comprehensive discovery of endogenous Argonaute binding sites in Caenorhabditis elegans. Nat Struct Mol Biol 17: 173-179. 


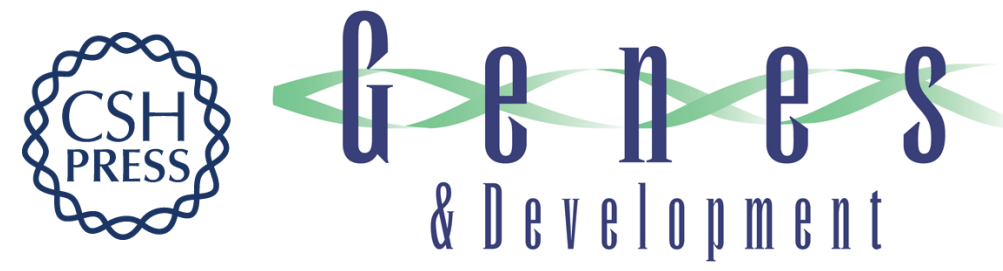

\section{Two new and distinct roles for Drosophila Argonaute-2 in the nucleus: alternative pre-mRNA splicing and transcriptional repression}

J. Matthew Taliaferro, Julie L. Aspden, Todd Bradley, et al.

Genes Dev. 2013, 27: originally published online February 7, 2013

Access the most recent version at doi:10.1101/gad.210708.112

Supplemental http://genesdev.cshlp.org/content/suppl/2013/01/31/gad.210708.112.DC1
Material

References This article cites 56 articles, 15 of which can be accessed free at: http://genesdev.cshlp.org/content/27/4/378.full.html\#ref-list-1

License

Email Alerting

Service
Receive free email alerts when new articles cite this article - sign up in the box at the top right corner of the article or click here.

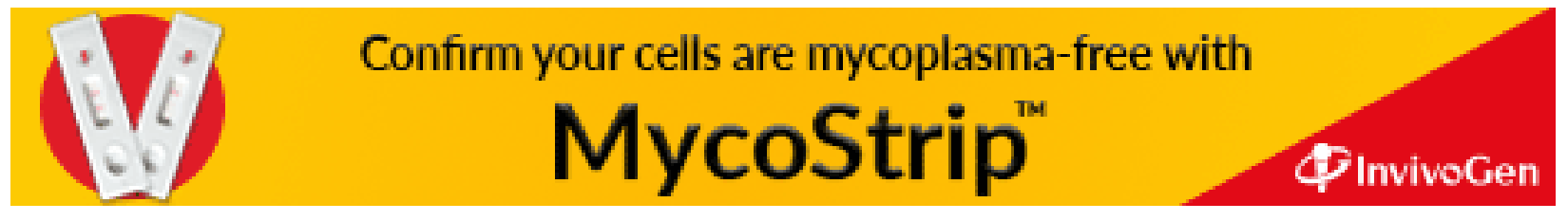

